\title{
Valuing Physical and Social Output: A Rapid Assessment of a London Community Garden
}

\author{
Victoria Schoen ${ }^{1, *}$, Silvio Caputo ${ }^{1}$ and Chris Blythe ${ }^{2}$ \\ 1 Kent School of Architecture and Planning, University of Kent, Canterbury, Kent CT2 7NR, UK; \\ s.caputo@kent.ac.uk \\ 2 Social Farms \& Gardens, The Greenhouse, Hereford Street, Bristol BS3 4NA, UK; chris@farmgarden.org.uk \\ * Correspondence: v.schoen@kent.ac.uk; Tel.: +44-1227-824701
}

Received: 4 June 2020; Accepted: 2 July 2020; Published: 6 July 2020

check for updates

\begin{abstract}
The value of urban farms and gardens in terms of their potential for supplying a healthy diet to local residents is well known. However, the prime objective of these spaces often differs from one of food production with this being the means by which other outputs are achieved. Valuing these spaces that provide diverse benefits is therefore a complex exercise as any measure needs to incorporate their physical as well as their social outputs. Only through such an integrated approach is the true value of these gardens revealed and the scale of their potential for contributing to health agendas made apparent. Social return on investment studies can be heavily resource dependent and the rapid cost benefit approach advanced here suggests that with limited expertise and minimal invasion of volunteer and beneficiary time and space, a public value return on investment ratio can be estimated relatively rapidly using an 'off the shelf' tool. For the food growing area of a London community garden, a return on investment of $£ 3$ for every $£ 1$ invested is calculated. This demonstrates the contribution that community gardens can make to social wellbeing within cities and justifies a call for further recognition of these spaces in urban planning policy.
\end{abstract}

Keywords: urban agriculture/growing; community gardens; social cost benefit analysis

\section{Introduction}

The diverse benefits of community gardens have been widely reported in the literature [1-5] and are evident on numerous fronts including economic gain, environmental benefits, contributions to society, and improvements to a population's health and wellbeing. Whilst many previous studies have described and quantified the benefits from one dimension, research that has simultaneously quantified more than one element is lacking. This dearth of quantitative evidence regarding the contribution of community gardens risks failing to give the sector the objective, and potentially financial, recognition that it deserves.

As a contribution to the debate on the monetised benefits of community gardens, this paper uses a rapid cost benefit methodology to put a value to the social benefits emanating from one garden in central London and combines this with the economic value of fruit and vegetables produced. It calculates the public value return on investment (ROI) achieved by the garden and subjects this to various proposed changes in garden organisation to assess what the impacts are on this indicator. The approach has been developed and applied partly in response to calls from the community garden sector in the UK for a rapid assessment tool that has peer-review status and that can demonstrate the financial value of the garden's intangible outputs alongside their more conventional produce.

These intangible outputs, the multiple social benefits of community gardens, are much quoted in the literature. These spaces bring people together to work with one another, helping them to overcome loneliness and exclusion, to develop a skill as well as generating feelings of happiness and a 
sense of self-worth [6-8]. Gardens provide training opportunities for people of all ages and from all backgrounds as well as being able to help educate younger members of society in the origins of the food on their plates. Community gardens break up so-called food deserts, allowing local populations to access previously unavailable healthy food and school children to try foods that they would perhaps have not have chosen without the education or improved accessibility [6].

Fruit and vegetables direct from the garden often look more appealing and are certainly fresher, with the likelihood that uptake will be increased [5,9]. Gardeners and those living in communities surrounding the garden benefit from the produce that is on offer, particularly as prices may be lower as a result of the short supply chains. Better diet can help towards better physical health and help to reduce the burden of obesity and related illness which is prevalent in the UK [10]. The physical act of gardening also helps to maintain fitness, can improve mental health and lead to more healthy lifestyles [11]. For the UK community gardener, passing time and working in the garden brings personal advantage and simultaneously creates benefit for society and the public good, thereby enhancing individual gain.

In the UK, there is growing support for therapeutic and prescriptive gardening to assist individuals to overcome or live with mental health conditions [2,12-14]. Although acknowledging that it is difficult to specifically attribute improvements in mental health to gardening activities, there are a range of studies that report better social interactions between garden users, improved physical activity and general quality of life [15]. Mondelēz's Health for Life in the Community programme reported in 2017 [16] that $87 \%$ of survey respondents had met new people since participating in its outdoor programme of Green Gym sessions and healthy eating sessions demonstrating the value of outdoor activity for reducing isolation and feelings of loneliness. Howarth et al. [15] having reviewed the body of evidence on the impact of gardens on physical and mental health and wellbeing, summarise the areas where gardens contribute as being: reduced social isolation; improved physical activity; improved nutritional intake; reduced anxiety and stress; reduced depression; and, individual and community wellbeing [15].

However, studies that value both the physical as well as the social outputs of community gardens specifically are few. This may be due to the complexity of measuring social outcomes [17] as well as the time requirement for this and for recording the physical output of community spaces. Measurement tools have been developed (for example, Farming Concrete [18], Harvest-ometer [19], and MYHarvest [20] are all online tools for recording farm or garden output). However, these do not allow for a valuation of garden produce over time for individual gardens while simultaneously putting a monetary value to the wellbeing improvements recorded by those volunteering in the gardens.

Buckley and Peterson [21] provide a basic guide to cost benefit analysis (CBA) for 'urban agriculture' but examples of the application of this methodology are absent. A social return on investment (SROI) study was completed for Gorgie City Farm Community Gardening Project in 2011 [22]. An SROI "measures change in ways that are relevant to the people or organisations that experience or contribute to it. It tells the story of how change is being created by measuring social, environmental and economic outcomes and uses monetary values to represent them" [23]. It largely derives from cost benefit analysis (CBA) but is much more heavily dependent on stakeholder involvement in determining measurement indicators [17]. In this way, SROI is more likely to include benefits that are obvious to service users, but perhaps less obvious in terms of financial indicators. Because of the resulting divergences in sets of indicators between organisations, it is recommended by the SROI Network that results are not compared between organisations but may be used over time within an organisation to study the effects of internal changes. Where a study is evaluative as opposed to a forecast, there is a need to report on the outcomes achieved and if data is not regularly collected as a project progresses, then it can take many months to gather this data through contact with various stakeholders [23].

The Gorgie City Farm SROI found a ratio of $£ 1: £ 3.56$, i.e., for every pound invested in the project in 2009, a total of $£ 3.56$ of social value was generated. Despite such a return, Gorgie City Farm closed at the end of 2019. It has since reopened, but its initial difficulties demonstrate how a lack of recognition of its substantial contribution to society makes it difficult to continue to operate with limited funds. 
In this SROI analysis, no allowance appears to have been made for any physical output from the project, with all benefits accrued being social returns to the various beneficiary groups.

Other food and community based SROI studies have been completed, but not for community gardens per se. A 2013 study by the University of Gloucestershire's Countryside and Community Research Institute (CCRI) of three food growing case study projects from the Big Lottery funded Local Food programme found a return on investment (ROI) of $£ 6$ to $£ 8$ for every $£ 1$ invested in the programme in terms of economic and social returns [24]. A study that looked at the SROI of The Wildlife Trusts' volunteering programmes found an ROI of $£ 6.88$ for every $£ 1$ invested for people with low levels of wellbeing at the start of the programme, and an ROI of $£ 8.50$ for every $£ 1$ invested for people with average to high wellbeing at the start of the programme [25]. A 2016 SROI evaluation of The Conservation Volunteers' Green Gym programme that provides opportunities for volunteers to work together in outdoor activities, found an ROI of $£ 4$ for every $£ 1$ invested [26].

SROI derives from CBA [27], a methodology that allows for the inclusion of the social and environmental effects of a project or other intervention but is less heavily dependent on stakeholder engagement than SROI, possibly allowing a more rapid analysis to be undertaken. The approach applied in this paper to value the costs and benefits of a London community garden follows a cost benefit methodology rather than an SROI.

The community gardening sector makes a valuable contribution in terms of social benefits but harnessing any income as a result of this is difficult without demonstrating the monetary value of such gardens to society. Community gardens earn an income from sales of produce and outreach activities and they use this, as well as grant income, to fund their social provision. These activities generate little or no income. Putting a monetary value to the services provided should assist the sector in gaining recognition for the savings it makes for society. It also adds to debates on the future of the UK social services sector and the potential role of organisations offering therapeutic gardening sessions as a means of reducing the burden on the NHS. Overweight and obesity alone are forecast to cost the NHS $£ 9.7$ billion by 2050 and the wider annual cost to society will reach $£ 49.9$ billion by this time [28]. Barry and Blythe [2] identify these predicted costs as one of the drivers behind increased dialogue between health and 'green' organisations, increased focus by the NHS on improving its own greenspaces, and increased use of social prescribing.

The current research has three main objectives. The first is to demonstrate the application of an off-the-shelf tool to calculate the cost to benefit ratio of a London community garden. The tool selected has been used to evaluate large public sector projects but as yet there is no evidence of its application in smaller scale community-led initiatives. Using a simplified CBA tool allows non-experts who would not be confident with conventional CBA methodology to complete a rapid summary of garden 'performance' and could help with garden planning when different planting schedules or social activities are being considered. Secondly, by explaining the approach to cost benefit analysis used for this case study garden, it is anticipated that the tool will become more accessible to those working in community gardens and potentially other community based initiatives whose experience of using the method of analysis is limited. Being relatively simple to conduct, it allows for implementation by non-trained staff in a short time period, acknowledging the many demands on frequently overstretched garden employees and volunteers. These first two objectives are addressed in Section 3 of the paper where the implementation of the tool is explained and the relevance to the community garden discussed.

The third objective of the paper is to use the tool to demonstrate the social value of one community garden in London and to discuss the implications of such value in terms of policy. Calculating the public value return on investment provides the garden with a means to introduce hard data into funding applications. Much of the SROI work done to date has been reported in project documents and whilst valuable to the organisation and its funders, lacks the peer review that academic journal publication offers. By introducing a more formal valuation of the community garden sector to the academic arena should help to validate claims made in future funding applications put forward by this, and hopefully 
other, community gardens in the UK. It should also enable them to gain greater recognition in urban planning and food policy debates. This last objective is addressed in the Discussion in Section 4.

\section{Methods}

Using a published tool, the method employed here calculates the public value return on investment of a London community garden. Public value represents the overall benefit to the public of a project or initiative and includes improved health and wellbeing as well as economic growth [29]. The analysis takes data from in-depth interviews with staff at a London case study garden and combines this with information gathered by the FEW-meter project (see Appendix A for a description of the project). In the UK, nine case study community gardens in London recorded harvest data during the 2019 growing season. The case study garden considered in this paper was one of the nine FEW-meter participants and their harvest data was used to inform the analysis presented. In addition, volunteers to the nine gardens were asked to complete a short questionnaire that included a section on the impact on their health and wellbeing as a result of participating in the garden. The results of this survey were used to derive the 'affected population' estimates for the CBA, as described later in the paper.

The cost benefit tool selected for the analysis was the Greater Manchester Combined Authority (GMCA) Cost Benefit Analysis (CBA) Excel tool [30] that allows for the calculation of the return on investment in the community garden. This tool was initially developed by the research team at GMCA in 2011 and was adopted as supplementary guidance to support the CBA recommendations of the HM Treasury Green Book (Central Government Guidance on Appraisal and Evaluation) [29,31] in 2014. The tool has been continually updated and used widely to evaluate the financial, economic and social benefits accruing to individuals and businesses as a result of different projects or interventions. Examples of its application by local and national government, CSOs and emergency services are available [32-35].

A team from GMCA provided training to volunteers and employees of gardens that are members of Social Farms \& Gardens in March 2019 in the basics of using the CBA tool and provided a short manual on the key elements of how to apply the methodology [36]. The decision to apply the tool in a FEW-meter project case study garden came as a result of the feedback from this training, where attendees noted that it was, 'Very useful training of a critical area for improving services and increasing access to funding' and that the tool 'can demonstrate benefits to service users in the whole organisation, good for grant applications' and its application would be, 'a way to quantify our value to the borough' [37]. However, participants also mentioned the need for a more simple tool/model and in later discussions with FEW-meter garden staff who attended the event there was confirmation of its potential usefulness but concerns about the complexity of its application.

Further detail on the mechanics of this tool are available on GMCA website: it uses pre-uploaded reference guides to value the benefits from different social outcomes of a project. In discussions with the garden concerned, the tool has been adapted to fit the specific circumstances in terms of size and make-up of beneficiary groups, retention rates and expected outcomes, with assumptions and measurements outlined below. Whilst two outcomes and four benefits were selected for this case study, the tool offers a menu of many other different potential outcomes from social interventions. For example, where a garden runs classes for school children or training sessions for the unemployed, outcomes such as reduced truancy or increased employment may be selected to measure impact, with values for these benefits already included in the model.

As much of the valuation data is already made available through the GMCA tool, it offers a relatively 'rapid' means by which to complete a CBA. This term borrows from the development literature where a 'rapid rural appraisal' is carried out by a team of staff from different disciplines in a short period, making use of secondary data and more informal data collection procedures [38-40]. This recognises the many demands on garden staff who are frequently employed part-time, on fixed term contracts dependent on grant funding with a busy schedule of volunteers and visitors to organise in addition to garden administration. The simplified CBA methodology advanced here does not 
include the depth and rigour of analysis that is usual in an economist-led evaluation, but its purpose is to provide a methodology that is accessible to a wider audience which would not be experienced in the use of conventional CBA. One of the authors is a community gardening practitioner and is aware of the need amongst urban gardeners and growers of a method to quantity their garden's contribution to society that meets these requirements.

A first iteration of the model was run using data obtained from the case study garden and the findings from this were discussed with the garden staff. After this, the model was adjusted to allow for modifications in some of the underlying assumptions regarding the numbers benefitting from participation in the garden. The results of this second iteration are described here.

\section{Computing the CBA}

In order to demonstrate how the CBA tool can be used within the community garden setting to generate a rapid assessment of physical and social output and to assist with internal planning, it was applied here to the food growing area of a London community garden. The garden (illustrated in Figure 1) was established by the local community in the early 1980s and aims at improving the physical and emotional wellbeing of those living and working in the locality and surrounding areas. It offers a range of facilities, including a football pitch, a children's play area, a café, community rooms, a safe area for mother and baby groups, small allotments for local growers and a community food growing area. There are numerous activities on offer: sports training for young people, community classes that cross the age divide, horticultural therapy for adults with learning disabilities and mental health issues and sustainable food growing to supply the onsite vegan café. The total site occupies approximately $1400 \mathrm{~m}^{2}$ with the food growing area accounting for about one quarter of this space $\left(350 \mathrm{~m}^{2}\right)$.
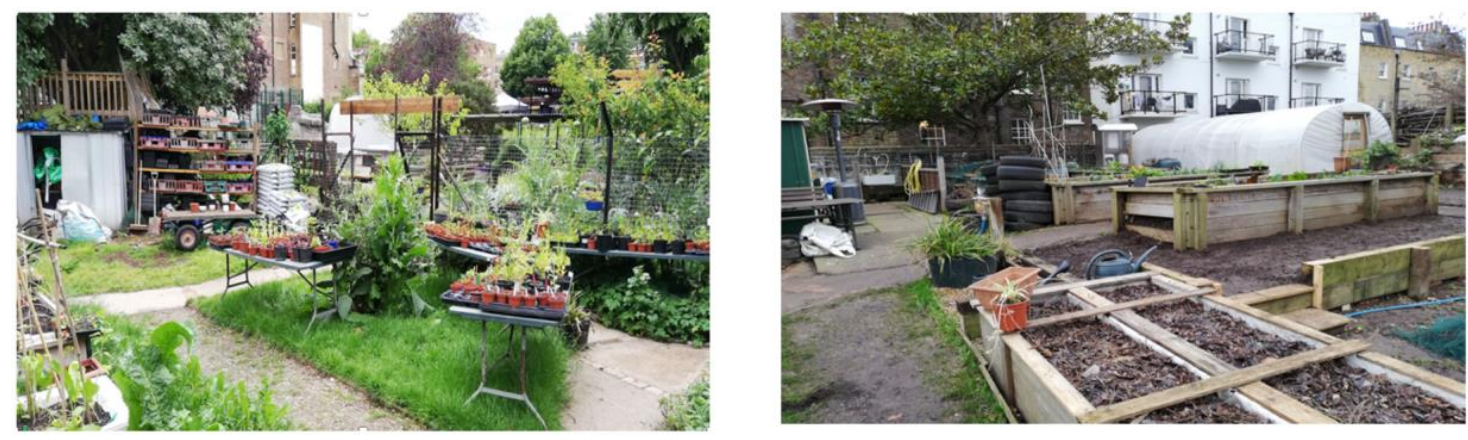

Figure 1. Food growing area of the case study London community garden.

Project income for the year to March 2019 totalled approximately $£ 371,000$ of which $60 \%$ was earned from room and pitch hire and sales from the café; $27 \%$ came from grants and $12 \%$ from the local authority (and 1\% from interest earned). The financing from the local authority will draw on taxpayer resource and that is an additional cost to society reflected in a higher deadweight loss from the operation of the food growing area. However this wider effect is not considered in the simplified CBA model as it is presented here.

The CBA is formed of two parts-the presentation of costs incurred by the project over the course of the year and calculation of the value of the observed benefits from the project in the same year.

\subsection{Assessing the Costs}

Cost data was collected during an interview with the project director in which all invoices for the project for 2019 were reviewed. From these, the costs relating to the food growing area were selected, and for some that applied to the project as a whole, a proportion was attributed to the food growing part. There are six different types of cost, shown in Table 1. 
Table 1. Costs of garden operation in 2019

\begin{tabular}{ccc}
\hline Cost Type & Detail & Total Cost 2019 \\
\hline Costs applying to whole site & Water, rent, refuse collection, business rates, \\
insurance & 4476 \\
Garden maintenance & Maintenance of the food growing area & 637 \\
Consumables & $\begin{array}{c}\text { Seeds, petrol, compost, pots, garden } \\
\text { implements }\end{array}$ & 1038 \\
\hline $\begin{array}{c}\text { Replacement costs } \\
\text { Salaries and associated } \\
\text { employment costs }\end{array}$ & Small garden tools & 221 \\
Volunteer labour input & Salaries, training, DBS checks, travel & 41,098 \\
TOTAL COST & 3571.5 total hours of volunteer time @ \\
& E10.55 per hour (London Living Wage) [41] & 37,679 \\
\hline
\end{tabular}

${ }^{1}$ These are taken as $25 \%$ of the cost for the entire site, based on an estimation that the food growing area accounts for $25 \%$ of the physical space.

1. Costs applying to the whole site: these include water, rent, rubbish collection, business rates and insurance and apply to the whole garden area. In agreement with the project director, for the CBA, these are estimated at one quarter of the total project cost, based on the physical area occupied by the food growing area.

2. Garden maintenance: these are costs involved in maintaining the garden area such as repairs to infrastructure and Skip hire.

3. Consumables: these are annual costs for items used for food and plant production, such as seeds, compost and petrol.

4. Replacement costs: these are directly attributable to the food growing area and include items such as secateurs, watering cans, gloves and sharpening tools. A similar outlay is made on such small tools each year.

5. Salaries and associated employment costs: Salaries allow for 2.2 FTE staff plus training and DBS costs.

6. Volunteer labour input: there are four main groups of volunteer gardeners working in the food growing area. Whilst these individuals receive no payment, in the CBA their time is valued, on the assumption that without this labour input, paid labour would be employed. The issue of valuation of volunteer time is discussed further in Section 3 of the paper. The groups of volunteers are as follows:

- Adults with learning disabilities from a local college: $399 \mathrm{~h}$ of unpaid labour per year.

- Adults with mental health and associated issues: $630 \mathrm{~h}$ of unpaid labour per year.

- Elderly gardeners: $1980 \mathrm{~h}$ of unpaid labour per year.

- $\quad$ Fit adults: $562.5 \mathrm{~h}$ of unpaid labour per year.

This gives a rounded total of $3572 \mathrm{~h}$ of unpaid labour per year. On the advice of the project manager, this has been valued at the 2018/19 London Living Wage rate of $£ 10.55$ per hour, the rate on which the garden bases its staff salaries. This is similar to the figure of $£ 10$ per hour suggested by the Heritage Fund for the lowest of three grades of volunteer labour: Professional (£50 per hour), Skilled ( $£ 20$ per hour) and Volunteer ( $£ 10$ per hour) [42].

\subsection{Assessing the Benefits}

Assessing the benefits within a CBA, simplified and conventional, is more complex given that health and social benefits are difficult to quantify and thus to value. Social benefits are achieved by improvements in wellbeing but such a qualitative indicator is difficult to value. Vardakoulias [27] 
suggests that many studies draw values for benefits from other studies so that the 'wellbeing values' used in many analyses are very rarely based on empirical research. The complexity of the valuation is compounded by the absence of a counterfactual: it is difficult to establish how much of any improvement in a person's wellbeing is due to visiting the garden and how much improvement would have occurred without these visits.

The GMCA CBA tool applied here uses previously identified data sources to attribute monetary values to the qualitative benefits flowing from a project or intervention, in this case the food growing area of the case study garden. The tool presents an extensive list of possible outcomes stemming from projects concerned with social interventions. Part of the analysis performed here involved selecting the outcomes most likely to be achieved through the work of a community garden. This was based on a review of the evidence on the health and social impacts of involvement in community and allotment gardens. The studies, largely taken from the Howarth et al. review [15], are listed in Table 2. These supported the selection of two potential outcomes from gardening from the GMCA list: 'Improved wellbeing of individuals' and 'Reduced hospital admissions'. The specific benefits to individuals of these outcomes are also listed in Table 2.

Table 2. Literature supporting choice of outcomes and benefits.

\begin{tabular}{ccc}
\hline Outcome $^{2}$ & Benefit ${ }^{2}$ & $\begin{array}{c}\text { Literature Sources to Support This as a } \\
\text { Benefit of Urban Growing }\end{array}$ \\
\hline & Increased confidence/self-esteem & Wood et al. [43] \\
Hoffman et al. [44], [45] \\
Kotozaki [46] \\
Bragg and Atkins [47] \\
Improved wellbeing of individuals
\end{tabular}

${ }^{2}$ Outcomes and benefits are taken from the GMCA CBA model.

Use of the 'Improved wellbeing of individuals' outcome was discussed with the project manager and the head gardener at the case study garden and both supported this. They were less convinced about the second potential outcome, 'Reduced hospital admissions' as a result of improved health, citing the difficulties of directly linking garden attendance with reduced need for GP or hospital care. The effect of including this was therefore tested in the sensitivity analysis where 'Reduced hospital admissions' was included as a potential outcome to observe the effect on the public value cost benefit ratio. This latter outcome is shown as a fiscal benefit in the simplified CBA model, representing monetary saving to the NHS as a result of prospective patients not needing to seek treatment. 


\subsubsection{Identifying the 'Affected' Population}

Having identified the benefit indicators for the food growing area, it was necessary to put values to these, starting with numbers of gardeners likely benefitting from attendance (the 'target population'). Discussions and observation at the garden allowed for the identification of four main beneficiary groups, the same groups that were included in the costs in terms of their volunteer labour: adults with learning disabilities from a local college; adults with mental health and associated issues; elderly gardeners; and fit adults.

From the target population, an estimate was needed of the 'affected population', that is the proportion likely to benefit from the outcome of 'Improved wellbeing' (consisting of increased self-confidence, reduced isolation and improved emotional wellbeing).

The proportions for each benefit were taken from the results of a volunteer survey in London for the FEW-meter study. This asked garden volunteers how involvement in the garden had helped them on a number of social indicators, including their self-confidence, their interactions with others and on their overall mood. For the outcome 'Improved wellbeing of individuals' in the CBA the percentage of FEW-meter volunteers responding positively to each of these three indicators has been used to calculate the likely proportion of the population in the case study garden to see an improvement in wellbeing. The proportions used were calculated as shown in Table 3.

Table 3. Percentages to apply to calculate 'affected population' in CBA.

\begin{tabular}{ccc}
\hline $\begin{array}{c}\text { FEW-Meter Indicator on } \\
\text { Volunteer Survey }\end{array}$ & CBA Benefit in GMCA CBA Tool & $\begin{array}{c}\text { \% of FEW-Meter Respondents Marking as } \\
\text { Strong or Slight Positive Effect from } \\
\text { Gardening (n = 44) }\end{array}$ \\
\hline Effect on self-confidence & Increased self-confidence/ & $68 \%$ \\
Effect on interactions with others & self-esteem & $86 \%$ \\
Effect on overall mood & Reduced isolation & $93 \%$ \\
\hline
\end{tabular}

So, for example, if 100 people attended the garden on a regular basis, it could be assumed that 68 would be likely to feel an improvement in self-confidence, 86 would see a reduction in feelings of isolation, and 93 would see an improvement in their emotional wellbeing. The size of the likely affected population once these percentages have been applied are shown in Table 4 with the reasoning behind the additional rows in Table 4 discussed below.

Table 4. Calculation of public value benefit for 'Improved Wellbeing of Individuals' outcome

\begin{tabular}{|c|c|c|c|c|}
\hline & \multicolumn{3}{|c|}{ Benefit } & \multirow[b]{2}{*}{$\begin{array}{c}\text { Total Public Value } \\
\text { Benefit }\end{array}$} \\
\hline & $\begin{array}{c}\text { Increased } \\
\text { Confidence/Self-Esteem }\end{array}$ & Reduced Isolation & $\begin{array}{l}\text { Emotional } \\
\text { Wellbeing }\end{array}$ & \\
\hline a.Size of target population & 89 & 89 & 89 & \\
\hline b.Percentage affected & $68 \%$ & $86 \%$ & $93 \%$ & \\
\hline c.Likely affected population & 61 & 77 & 83 & \\
\hline $\begin{array}{l}\text { d.Level of engagement with } \\
\text { affected population }\end{array}$ & $100 \%$ & $100 \%$ & $100 \%$ & \\
\hline e.Retention rate & $60 \%$ & $60 \%$ & $60 \%$ & \\
\hline f.\% impact & $30 \%$ & $30 \%$ & $30 \%$ & \\
\hline g.\% deadweight & $0 \%$ & $0 \%$ & $0 \%$ & \\
\hline h.Public value per person & $£ 3500$ & $£ 8500$ & $£ 3500$ & \\
\hline i.Inflation adjustment & 82.938 & 82.938 & 82.938 & \\
\hline j.Public value benefit & $£ 45,971^{3}$ & $£ 141,197^{3}$ & $£ 62,872^{3}$ & $£ 250,041$ \\
\hline
\end{tabular}

${ }^{3}$ These figures are calculated in the GMCA CBA tool using the formula: $\mathrm{a} \times \mathrm{b} \times \mathrm{d} \times \mathrm{e} \times(\mathrm{f}-\mathrm{g}) \times \mathrm{h} \times(100 / \mathrm{i})$ and any discrepancies are due to rounding.

\subsubsection{Level of Engagement and Retention Rate}

Level of engagement with the 'affected population' attending the garden refers to the percentage of this population with which it is possible to engage through the activity in question, i.e., gardening. 
In the scenario presented, it is assumed that given the groups of gardeners are small and are working with a trained leader, engagement will be high and the rate of engagement is therefore given as $100 \%$.

The retention rate refers to the percentage of the group that continue with the activity over the course of the year. A $60 \%$ rate has been allowed for in the analysis that reflects the recorded attendance rates of current participants in the groups that the garden organises. This is later tested in the sensitivity analysis.

\subsubsection{Impact and Deadweight}

The analysis is based on the assumption that those attending the garden see an overall improvement in their wellbeing measured through increased self-confidence and self-esteem, reduced isolation and improved emotional wellbeing. The extent to which an improvement in these benefits is experienced is reflected in the impact percentage. In the initial scenario, this is valued at $30 \%$ but given this is difficult to quantitively assess, it is tested later in the sensitivity analysis. Deadweight is set to zero on the assumption that in the absence of the supported group it may be that the participants' wellbeing is unchanged. The tool deducts deadweight from impact to give a net percentage improvement in wellbeing that is due to the project.

\subsubsection{Public Value per Person}

The row in Table 4 labelled, 'Public value per person' refers to the monetary value (the shadow price) that is given to the improvement in wellbeing (increased self-confidence and self-esteem, reduced isolation and improved emotional wellbeing) brought by attendance at the garden. This value is pre-loaded into the GMCA model with an explanatory reference given as: 'Bespoke analysis carried out by New Economy Manchester. Based on apportioning the willingness to pay value for the QALY impact of depression ( $£ 35,400$ per annum) across all the domains of wellbeing as set out in the National Accounts of Wellbeing' [30]. At a macro level, the calculation of value was based on the NICE benchmark for the full social value of a QALY (Quality Adjusted Life Year) of $£ 60,000$ [66]. The indicators used to assess social benefits were drawn from the National Accounts of Wellbeing [67] and values apportioned according to analysis undertaken by Cox et al. [68]. Final adjustments to the values were made following meetings with the Department of Health by the tool developers to adjust the proportion of a QALY related to depression [69].

\subsubsection{Inflation Adjustment}

The GMCA tool uses 2009/10 prices to value the per person public value benefit of engaging in an activity, as established when the tool was originally developed. To account for inflation from 2009/10 to 2019/20, the GDP deflator allows for price inflation over the 10-year intervening period and calculates monetary benefits at 2019/20 prices.

In the model, the 2009/10 GDP deflator is calculated as 82.939 when $2019 / 20$ is the base year (100.00). Applying this index to the 2009/10 per unit public value figures of $£ 3500$ and $£ 8500$ gives $2019 / 20$ values of $£ 4220$ and $£ 10,248$ respectively. The tool automatically makes these adjustments.

\subsubsection{Public Value Benefit Calculation}

Using the assumptions regarding affected population, engagement, retention, impact and deadweight, as previously described, and applying the GDP deflator and public benefit values as used by the GMCA CBA tool, the social value of the benefits the garden offers are shown in Table 4 to total $£ 250,041$.

\subsubsection{Value of 'Sales' from Food Growing Area}

In the GMCA CBA tool, the value of produce from the garden is listed as an 'offset cost' so that the total sales value of plants, fruit and vegetables produced in the garden is taken off the total cost of the 
food growing area, before comparing with the social benefits. For the case study garden, all produce was weighed and recorded during the 2019 growing season. This produce is not sold but supplies an on-site café and was valued at $£ 1500$ for approximately $205 \mathrm{~kg}$, using organic price data from the Soil Association [70]. In addition, the garden manager estimated the value of plant sales to visitors to be approximately $£ 1000$ for the year. For purposes of convention, here the total sales value of $£ 2500$ is added to the value of benefits before the comparison with costs is made to create the cost benefit ratio. This addition is shown in Table 5 .

Table 5. Calculation of total benefits from the food growing area of the garden

\begin{tabular}{cc}
\hline & Value of Benefits \\
\hline Total public value benefit & $£ 250,041$ \\
Sales of fruit and vegetables & $£ 1500$ \\
Plant sales & $£ 1000$ \\
\hline Total benefits & $£ 252,241$ \\
\hline
\end{tabular}

Comparing this total benefit value of $£ 252,241$ with total costs of $£ 85,148$ (Table 1 ) gives a cost benefit ratio (public value ROI) of $£ 1: £ 2.96$, that is, for every $£ 1$ invested in the garden, $£ 2.96$ of public value is created.

\subsubsection{Additional Beneficiaries}

Additional beneficiary groups could be added to the analysis- those visiting less formally as well as those working in the neighbourhood or passing by on a regular basis. These have not been included as the analysis is specifically about the food growing area of the project and those attending for non-food growing related purposes would be unlikely to visit this part of the project. Passers-by are less likely to see this part of the project area, being tucked away in a far corner of the site. However, if the analysis was extended to include all aspects of the project, a more in-depth approach could include a survey of local residents and businesses.

\subsection{Sensitivity Analysis}

The calculation of a public value ROI of $£ 2.96$ for every $£ 1$ invested in the food growing area of the project is based on a number of assumptions regarding engagement, retention rates, impact and deadweight amongst others. These are largely taken from interviews with project staff, from analysis of the FEW-meter volunteer survey and from discussions with the GMCA CBA tool designer. In order to check the effects of changes to these components as well as to determine what the critical rates are for the garden in terms of generating a positive return, sensitivity analysis was carried out on a number of the assumptions.

\subsubsection{Retention and Impact}

These were estimated at $60 \%$ and $30 \%$ respectively in the model as shown in Table 4 . The $60 \%$ was based on garden attendance records. However, impact was more difficult to assess. Bagnall [25] attributes $80 \%$ of benefits of attendance at a Wildlife Trust volunteer programme as being due to the programme. Pank [22] attributes 58\% of mental health improvements by garden volunteers as being due to garden participation. These suggest the estimate of $30 \%$ used in this study to be quite conservative. Table 6 shows the effect on the ROI of adjusting the retention and impact rates. 
Table 6. Adjusting retention and impact rates.

\begin{tabular}{ccccc}
\hline & & \multicolumn{3}{c}{ Retention Rate (Percentage) } \\
& & 40 & 60 & 80 \\
\hline \multirow{2}{*}{ Impact percentage } & 20 & 1.33 & 1.99 & 2.64 \\
& 30 & 1.99 & $\mathbf{2 . 9 6}$ & 3.94 \\
& 50 & 3.29 & 4.92 & 6.55 \\
\hline
\end{tabular}

If retention is held at $60 \%$ and impact is increased to $50 \%$, an improvement in the ROI to $£ 4.92$ is observed. If the garden has an interest in showing a return of almost 1:5, it might consider undertaking a survey with its volunteers to ascertain whether a $50 \%$ improvement in wellbeing as a result of garden attendance is a fair estimate. Maintaining retention at $80 \%$ over the course of a year may be more of a challenge. Clearly reductions in retention and impact do not serve the garden well: it could perhaps afford a reduction in retention to $40 \%$ if impact remains at $30 \%$ but if repeat attendance starts to drop off and volunteers note a reduction in contribution that the garden makes to their overall wellbeing the garden becomes less socially viable with an ROI of only 1:1.33.

\subsubsection{Value of Volunteer Labour}

The effect on the ROI of adjusting the valuation of volunteer labour while holding retention at $60 \%$ and impact at $30 \%$ are shown in Table 7 . In consultation with the project manager, it was agreed that in the absence of volunteer labour, it would be necessary to employ paid labour at the London Living Wage of $£ 10.55$ per hour. However, the productivity of this labour would be higher. The sensitivity analysis therefore looks at the impact of a $50 \%$ reduction in the wage rate to the volunteer gardeners, assuming that an active paid labourer could achieve the same output in half the time of the elderly or socially disadvantaged volunteers who frequently see time spent at the garden as a social activity. Table 7 shows an ROI of 3.81 at this reduced wage rate.

Table 7. Adjusting the valuation of volunteer labour.

\begin{tabular}{cccc}
\hline & $\begin{array}{c}£ 10.55 \text { per } \\
\text { Hour }\end{array}$ & $\begin{array}{c}£ 5.275 \text { per } \\
\text { Hour }\end{array}$ & $£ 0$ \\
\hline ROI & 2.96 & 3.81 & 5.32 \\
\hline
\end{tabular}

There is a debate in the literature concerning the valuation of volunteer hours [17,71]. Part of this derives from the fact that it is often not known what volunteers would be doing if they were not working in the garden: they may, for example, be employed in skilled, high wage jobs or they may be enjoying more leisure time. These two would have different opportunity costs. Vining and Weimer [71] suggest that if the volunteer derives an amount of satisfaction (utility) from the activity (gardening in this case) at least equivalent to the opportunity cost of the time they have spent volunteering, then perhaps their labour should be valued at zero for the purposes of the CBA. This was the approach used by Pank [22] in the base model: volunteers' time was however costed in the sensitivity analysis in that study to account for the fact that without the input from those volunteers, the gardens would not be so well maintained and the satisfaction of other stakeholders would fall. In the case study presented here, the utility or social value gained from volunteering is already accounted for in the benefits calculation but the sensitivity analysis includes a calculation without volunteer 'wages' to see the effect on the cost benefit ratio. As expected, when labour is valued at zero, suggesting attendees would not otherwise be using their time in a more productive manner, the ROI reaches £5.32. It is for the garden to decide how it wishes to use its CBA and therefore the most appropriate manner in which to treat volunteer labour for the purposes of the analysis. 


\subsubsection{Change in the Price of Fruit and Vegetables}

Currently produce from the garden is not sold but it has been given an imputed value in the CBA model, based on prices from the Soil Association [70]. This values the produce at organic, farm shop prices that are subject to variation according to seller, market and location. Given actual prices for produce sold are not available, prices applied are therefore selected subjectively and are subject to variation. However, when prices of fruit and vegetables are increased two-fold to $£ 3000$, there is only a very slight increase in the ROI to 2.98. A three-fold increase in the price of produce increases the ROI to 3. This demonstrates that the tool is quite robust to the source of prices used.

However, this result may be important in directing the input of the lead gardener, if the increased sales revenue stems from increased output rather than increased prices. Table 8 shows the effect on the ROI of such a two-fold increase in garden output at the expense of the lead gardener reducing the time spent supervising volunteers. Revenue from fruit, vegetable and plant sales is set at $£ 4000$ and the target population reduced to 79 .

Table 8. Increasing garden output and reducing volunteer numbers.

\begin{tabular}{ccc}
\hline Value of Labour per Hour & Retention Rate $\mathbf{6 0 \%}$ & Retention Rate $\mathbf{3 0} \%$ \\
\hline$£ 10.55$ & 2.65 & 1.35 \\
\hline$£ 5.275$ & 3.41 & 1.73 \\
$£ 0$ & 4.75 & 2.42 \\
\hline
\end{tabular}

With a reduced number of volunteers achieving social benefits, when value of volunteer labour is maintained at $£ 10.55$ per hour and retention rate at $60 \%$, the ROI falls to 2.65 . If increased focus on fruit and vegetable production reduces focus on volunteers and the retention rate falls to $30 \%$, then the ROI is reduced to a level of 1.35 where it may be considered less viable. If volunteer labour is costed at zero and retention stays at $60 \%$, then there is a healthy ROI of 4.75 but this is below the 4.92 achieved when produce output remained at a value of $£ 2500$, target population at 89 and impact was raised to $50 \%$. The garden could use such information to determine whether its future priorities lie with food output or with maximising the wellbeing that volunteers gain from working in the garden.

\subsubsection{Adding Volunteer Groups and Outcomes}

Once set up, the CBA tool can be used to forecast the effect on the ROI of changing the number and type of volunteer sessions offered as well as the potential outcomes from volunteering in the garden. Three scenarios are discussed here: including 'Reduced hospital admissions' as a possible outcome, adding an additional group for elderly gardeners and including a group for adults with alcohol addiction.

Including 'Reduced Hospital Admissions' as a Potential Outcome

It was stated earlier in the paper that staff at the project questioned the evidence that garden attendance reduced the need for GP or hospital care. Hence 'Reduced hospital admissions' was not included as a potential outcome in the original CBA. However, the addition of such an outcome is tested here as certainly there is evidence in the literature (see Table 2) to support this as a potential benefit from gardening. The results are shown in Table 9: in the GMCA CBA tool, the fiscal saving from a visit to hospital foregone is valued at $£ 1864$ at 2017/18 prices (adjusted using the deflator shown in Table 9) using weighted NHS data [72]. 
Table 9. Calculation of public value ROI when 'Reduced Hospital Admissions' is included as an outcome

\begin{tabular}{cc}
\hline Size of Target Population & $\mathbf{8 9}$ \\
\hline Percentage affected & $10 \%$ \\
Likely affected population & 9 \\
Level of engagement with affected population & $100 \%$ \\
Retention rate & $60 \%$ \\
$\%$ impact & $30 \%$ \\
\% deadweight & $0 \%$ \\
Fiscal value per person & $£ 1864$ \\
Inflation adjustment & 96.274 \\
Fiscal benefit & $£ 3102$ \\
Public value carried forward & $£ 250,041$ \\
\hline Produce sales & $£ 2500$ \\
\hline Total benefit & $£ 255,643$ \\
\hline Total costs & $£ 85,148$ \\
\hline Public value ROI & $\mathbf{1 : 3 . 0 0}$ \\
\hline
\end{tabular}

Keeping the engagement, retention, impact and deadweight rates the same, with volunteer labour valued at $£ 10.55$ per hour, results in an ROI of 3 when reduced hospital admissions are included. This very slight rise in the ROI is in part due to the low numbers included as the likely affected population but also as the fiscal benefit per person is small in comparison with the size of the public value benefits of improved wellbeing. The garden may consider that it is better to concentrate time on establishing robust impact data for its social outcomes than to spend time gathering evidence of its ability to generate fiscal savings that affect its ROI so little.

\section{Adding Additional Groups}

At the case study garden, the current ongoing group of elderly gardeners is oversubscribed and one consideration is to run an additional group for 20 adults on a second day of the week. This would necessitate an increase in staff costs of a half day per week and although it would lead to an increase in total public value, the ROI would fall slightly to 2.94 . When volunteer labour is given a zero value this rises to 5.85. Such a calculation could assist the garden in making a decision on whether to expand its numbers, as well as supporting a claim for further funding to support the additional group.

A final consideration is the addition of a group of 10 adults recovering from alcohol addiction, an idea suggested by the project manager as something that had been considered in the last year. These additional 10 adults add to the previously calculated public value from improved wellbeing value as well as creating fiscal savings of $£ 1800$ per person (adjusted for inflation) and an additional $£ 1398$ per person for public value benefits. These additional benefits are due to assumed reduced health and criminal justice costs. The valuations are based on NICE guidance documents $[73,74]$ as referred to in the GMCA CBA tool. With volunteer labour valued at $£ 10.55$ per hour, the ROI after the addition of this group is similar to the base case at 2.99 , rising to 5.67 when volunteer labour is valued at zero. In terms of garden planning, even using the base case with a retention rate of $60 \%$ and the London Living Wage assumed, there is a slight improvement in social outcome values and so it may be worth considering as an addition to its current offer.

\subsection{Data Needs for Community Gardens to Calculate a CBA}

The analysis above has highlighted how the GMCA CBA tool may be applied to a community garden and how the garden may use the results to assist with internal planning decisions, to monitor their performance and to write potential grant applications. Table 6 showed the importance of maintaining retention rates and either looking to increase these or to increase the effectiveness of the support groups in terms of helping attendees to see improved wellbeing. Section 3.2.2 discussed the 
valuation of volunteer labour and showed the extent to which this affects the ROI. Knowing the target audience for the results of the analysis will assist in directing the choice of valuation. Section 3.3.3 looked at how changes to the focus of the lead gardener affect the ROI and finally the paper considered the impact of additional groups or more emphasis being put on gathering data to support claims of fiscal savings.

In order for other community gardens to be able to undertake this analysis, they need to have the data to hand to undertake the CBA. Once this is gathered, the calculations can be completed rapidly to produce a first iteration of results which may be discussed with garden staff and volunteers. Data requirements include: input costs; harvest weights; weekly produce prices; number of organised groups running each week, numbers attending, turnover and characteristics of clients; and an estimate of the impact of group attendance and deadweight. In the case study presented here, some data has been taken from the FEW-meter project and some from interviews with garden staff. If the garden keeps accurate records of its purchases (quantities and prices), produce harvested over the course of the growing season, and groups attending on a regular basis, then the additional data demands to carry out similar analysis are minimal. A short before and after survey of attendees could confirm the impact of attending the garden on their perceived health and wellbeing in order to estimate the impact percentage needed for the CBA.

Valuing the produce from the community garden is a challenge where this is not sold but is directed to an onsite café, given to volunteers or used for communal lunches. Historical consistent and accurate price data is difficult to locate and if the garden was able to record prices from external sources such as the Soil Association as the growing season progressed, then valuing the produce at the end of the season would be an easier task.

Having established some basic record keeping at the community garden, it would be relatively simple for garden managers to use a pre-set model such as the GMCA CBA tool to allow them to view the overall social worth of their gardens and to see what the effect of any suggested organisational changes might be.

\subsection{Including Environmental Benefits}

As it stands the GMCA CBA does not allow for the inclusion of environmental benefits from urban gardens. This does need to be addressed if the model is further developed as environmental benefits from such green spaces are well known. The community garden produces food near to the population for which it is grown, thus reducing food miles and resultant carbon emissions [75]. Pollution is reduced [9]. Many potential enhancements to biodiversity from community gardens have been identified [76-78] as well as opportunities for improved drainage and overcoming the urban heat island effect. Gardeners, by creating and maintaining the garden, improve the environment and benefit from such improvements. To an extent, these benefits to the individual are captured in the social benefit listed as improved 'emotional wellbeing'. However, when community gardens are often the only green area within a part of the city, an indicator of environmental gain within the CBA should reflect this.

\section{Discussion}

The evidence in support of the benefits of urban farming and growing is compelling and the consensus is that involvement in this activity has a positive effect on physical and mental health, as well as resulting in the production of nutritious local food. The above analysis has put a value on the combined physical and social output from the case study community garden and its value is clear at both the micro and macro levels. At the level of the individual garden, the tool can be used to assist with internal planning, to justify funding applications and to allow comparisons for the same garden over time and between similar gardens to generate ideas for maximising garden benefits. At the same time, the analysis can be used at a macro level to demonstrate the contribution that such gardens make 
to society, with associated implications for urban planning and health policy. Demonstration of the value of community gardens using the public value ROI was the third objective of this paper.

Community gardens are one of the models for urban food production, which include allotments and city farms. All these models stem from a tradition of growing food in cities [79] motivated by issues such as subsistence or simply access to healthy food. Amongst these models, community gardens are those that most emphasise the social dimension of food production, using food as a catalyst for social amelioration. This role in supporting community social activities is well rehearsed in the literature [1,80-84]. Fêtes aimed at community-building and workshops for schools are only two examples of the social events that community gardens organise to generate the many benefits mentioned in the Introduction. The CBA presented here shows that, when a monetary value is assigned to these benefits, the social return is high and outnumbers the value of food produced. This bears some implications.

Firstly, it is important to clarify that without food such social returns would not exist. In fact, attributing a monetary value to material and immaterial benefits cannot justify a comparison between elements that are not comparable because both are essential. Yet, the considerable imbalance in value between these two elements may lead to questioning the viability of urban food production and to redirecting activities exclusively for social returns. It is therefore necessary to frame correctly findings of the CBA, the purpose of which is not to suggest that activities with a higher return should be prioritised, but rather to provide evidence (to policy-makers and to community garden managers) that, when translated into monetary advantages, services provided by the community gardens are in fact overlooked.

Secondly, it is worth considering the opportunity that community gardens offer as places that can provide social support services at a time in which the UK government, as well as in many other European governments, are curtailing state intervention. In the UK, Social Farms \& Gardens (the national organisation for community gardens and urban farms) represents over 1600 members of varied sizes (May 2020). Assuming the garden case studied here is representative of a middle sized community garden with modest food output and social benefits, a rough calculation $(1600 \times £ 200,000)$ gives a very approximate benefit of $£ 320$ million, $3 \%$ of the planned $£ 12.2$ billion spend on mental health in England by the NHS in 2018/19 [85]. Such powerful evidence may motivate policy makers to invest in these organisations thereby formalising the contribution to social wellbeing that they can offer. In fact, community gardens and other forms of urban farming have the potential to play a role in the three main policy areas receiving focus from the UK government: health, climate change and environment, and community cohesion/development. From a practitioner point of view, there is a need for effective urban policies that can turn this potential into actual impact.

In another policy area, it is also important to recognise the value of community gardens in delivering policy objectives such as those captured in the Mayor of London's Food Strategy [86]. The relationship between city food strategies/policies and the growth in community food movements has been recognised previously [87]; it is perhaps now time for a re-appraisal of such a relationship through the development of inter-sectorial strategies. In fact, there is the potential for community gardens to deliver multiple benefits in diverse areas such as food security, health and economic growth. But such multiple benefits can be elicited only if policy can join strategies from diverse sectors.

At present, there is little recognition at a national level that the tool commissioned by GMCA and based on the quantification of the willingness to pay in relationship to depression is a valid indicator, especially with regard to gardening activities. There are sporadic episodes of collaborations between individual GP surgeries and community gardens specialised in offering support to patients through mechanisms of social prescription (e.g., Sydenham Garden [88]). But these initiatives are not framed and probably not motivated by economic evaluations, rather medical evidence of the benefits accrued by contact with nature and physical exercise. Hence the importance that ROI analysis is recognised as critical evidence in policy. 
The need for stronger recognition of community gardens and farms within planning policy is also one which could benefit from the quantification this study provides, if it is replicable on a larger scale, and the results reflect those in this example. Some local authorities have already produced planning advice highlighting this, for example, Brighton \& Hove [89]; others make reference to urban farming and growing in their city plans, and the growth of the Sustainable Food Places movement [90] will also improve the nature of this debate.

\section{Conclusions}

The analysis has shown the applicability of the GMCA CBA tool to one London community garden and has given a detailed explanation as to how the CBA was undertaken. From this, ideally other community gardens in London and elsewhere will realise the advantage of performing a rapid CBA and the example provided here will be sufficient to enable such analysis to be carried out by others. In addition, the analysis has shown the contribution that the case study community garden in London makes to society and how, from a small base in terms of area covered, numbers employed and fresh produce output, it manages to achieve a 1:3 value ratio in terms of money in and social value produced. Undertaking a similar rapid CBA for other community gardens in London would allow these spaces to see how to maximise public value created. This could lead to recommendations for community gardens in terms of maximising societal productivity, either in terms of balancing fresh produce output with societal objectives, or deciding between which societal needs to focus efforts on, for example, more groups for elderly gardeners or more time for school visits. Using the CBA tool to demonstrate their full value to society may lead to greater recognition for these urban spaces, better funding as health resources are diverted from treatment to prevention, and a more sustainable future for urban green space.

Author Contributions: Conceptualization, S.C. and V.S.; methodology, V.S.; formal analysis, V.S.; investigation, V.S.; writing — original draft preparation, V.S.; writing—review and editing, V.S., S.C. and C.B.; visualization, V.S.; supervision, S.C.; project administration, V.S.; funding acquisition, S.C. All authors have read and agreed to the published version of the manuscript.

Funding: This research was undertaken within the FEW-meter project, funded under the JPI Urban Europe/Belmont Forum's call “SUGI-FEW Nexus” (grant number 2017/25/Z/HS4/030480_European Union's Horizon 2020 research and innovation programme GA No 730254), and ESRC grant number ES/S002170/2. The APC was funded by the University of Kent.

Acknowledgments: Special thanks to the staff and volunteers at Calthorpe Community Garden, London, for their assistance with harvest data collection and comments on the application of the CBA. The advice of David Morris, Little Lion Research, on use of the GBCA CBA tool, is also gratefully acknowledged.

Conflicts of Interest: The authors declare no conflict of interest.

\section{Appendix A}

The FEW-Meter (Food-Energy-Water) project is a five country study, funded through the call, 'Sustainable Urbanisation Global Initiative (SUGI)/Food-Water-Energy Nexus' (SUGI), jointly established by the Belmont Forum and the Joint Programming Initiative Urban Europe. The project investigates the use of energy, water and other resource use on case study farms and gardens in five countries (UK, US, Poland, France and Germany). Data is gathered over two growing seasons (2019 and 2020) to model the resource flows of urban agriculture, allowing the identification of methods to improve efficiency on-farm and also at a city scale. An online platform for urban food producers will be created to share knowledge and experience gained within the project. The project seeks to incorporate the physical output indicators with the social benefits offered by the garden in order to show how communities can be advantaged through engagement in growing while at the same time producing fruit and vegetables with methods and resources that are sustainable. 


\section{References}

1. Milbourne, P. Urban Community Gardening: Producing New Spaces of Social Nature in the City. In The SAGE Handbook of Nature; Marsden, T., Ed.; SAGE Publications Ltd.: London, UK, 2018.

2. Barry, V.; Blythe, C. Growing Pathways to Well-being through Community Gardens and Greenspace. Case Studies from Birmingham and the West Midlands, UK. In Pathways to Well-Being in Design Examples from the Arts, Humanities and the Built Environment; Coles, R., Costa, S., Watson, S., Eds.; Routledge: Abingdon, UK, 2018; pp. 76-96.

3. Dubová, L.; Macháč, J. Improving the quality of life in cities using community gardens: From benefits for members to benefits for all local residents. GeoScape 2019, 13, 68-78. [CrossRef]

4. Egli, V.; Oliver, M.; Tautolo, E. The development of a model of community garden benefits to wellbeing. Prev. Med. Rep. 2016, 3, 348-352. [CrossRef] [PubMed]

5. Alaimo, K.; Packnett, E.; Miles, R.A.; Kruger, D.J. Fruit and vegetable intake among urban community gardeners. J. Nutr. Educ. Behav. 2008, 40, 94-101. [CrossRef] [PubMed]

6. Van Tuijl, E.; Hospers, G.-J.; Van den Berg, L. Opportunities and Challenges of Urban Agriculture for Sustainable City Development. Eur. Spat. Res. Policy 2018, 25, 5-22. [CrossRef]

7. Armstrong, D. A survey of community gardens in upstate New York: Implications for health promotion and community development. Health Place 2000, 6, 319-327. [CrossRef]

8. Mourao, I.; Moreira, M.C.; Almeida, T.C.; Brito, L.M. Perceived changes in well-being and happiness with gardening in urban organic allotments in Portugal. Int. J. Sustain. Dev. World Ecol. 2019, 26, 79-89. [CrossRef]

9. Santo, R.; Palmer, A.; Kim, B. Vacant Lots to Vibrant Plots A Review of the Benefits and Limitations of Urban Agriculture; Johns Hopkins Center for a Livable Future: Baltimore, MD, USA, 2016.

10. Pourias, J.; Duchemin, E.; Aubry, C. Products from urban collective gardens: Food for thought or for consumption? Insights from Paris and Montreal. J. Agric. Food Syst. Commun. Dev. 2015, 5, $175-199$. [CrossRef]

11. Roberts, S.; Shackleton, C. Temporal Dynamics and Motivations for Urban Community Food Gardens in Medium-Sized Towns of the Eastern Cape, South Africa. Land 2018, 7, 146. [CrossRef]

12. Bragg, R.; Leck, C. Good Practice in Social Prescribing for Mental Health: The Role of Nature-Based Interventions; Natural England: York, UK, 2017; Volume 228.

13. Schmutz, U.; Lennartsson, M.; Williams, S.; Devereaux, M.; Davies, G. The Benefits of Gardening and Food Growing for Health and Wellbeing; Garden Organic and Sustain: London, UK, 2014.

14. Federation of City Farms and Community Gardens. Benefits of Community Growing: Mental Health; FCFCG: Bristol, UK, 2016.

15. Howarth, M.; Brettle, A.; Hardman, M.; Maden, M. What Evidence is there to Support the Impact of Gardens on Health Outcomes? A systematic Scoping Review of the Evidence; Sustainable Housing and Urban Studies Unit; The University of Salford: Salford, UK, 2017.

16. Blythe, C. Report to Mondelez International Foundation; The Conservation Volunteers: Doncaster, UK, 2017; Volume 5.

17. Arvidson, M.; Lyon, F.; McKay, S.; Moro, D. The Ambitions and Challenges of SROI; Third Sector Research Centre; University of Birmingham: Birmingham, UK, 2010; Working Paper 49.

18. Farming Concrete Farming Concrete. Available online: https://farmingconcrete.org (accessed on 1 June 2020).

19. Capital Growth the Harvest-Ometer. Available online: https://www.capitalgrowth.org/the_harvestometer/ (accessed on 1 June 2020).

20. MYHarvest. Available online: https://myharvest.org.uk (accessed on 1 June 2020).

21. Buckley, J.; Peterson, H.C. Preliminary Cost-Benefit Analysis for Urban Agriculture An Introduction; Community and Regional Food Systems Project: Michigan, USA, 2015.

22. Pank, H. Gorgie City Farm Community Gardening Project Social Return on Investment (SROI) Report; Federation of City Farms and Community Gardens: Edinburgh, UK, 2011.

23. Nicholls, J.; Lawlor, E.; Neitzert, E.; Goodspeed, T. A Guide to Social Return on Investment; The SROI Network: Liverpool, 2012.

24. Courtney, P. The Local Food Programme: A Social Return on Investment Approach. Final Report to the Royal Society of Wildlife Trusts; Local Food: London, UK, 2014. 
25. Bagnall, A.; Freeman, C.; Southby, K.; Brymer, E. Social Return on Investment Analysis of the Health and Wellbeing Impacts of Wildlife Trust Programmes; Leeds Beckett University: Leeds, UK, 2019.

26. Beishon, J.; Munoz, N. "I Feel Fitter and Better Being Outside" Green Gym Evaluation Report; TCV: Doncaster, UK, 2016.

27. Vardakoulias, O. Social CBA and SROI; NEF: London, UK, 2013; Volume 4.

28. Public Health England Health Matters: Obesity and the Food Environment. Available online: https://www.gov.uk/government/publications/health-matters-obesity-and-the-food-environment/ health-matters-obesity-and-the-food-environment-2 (accessed on 1 June 2020).

29. HM Treasury. Supporting Public Service Transformation: Cost Benefit Analysis Guidance for Local Partnerships; HM Treasury: London, UK, 2014.

30. Greater Manchester Combined Authority Cost Benefit Analysis. Available online: https://www. greatermanchester-ca.gov.uk/what-we-do/research/research-cost-benefit-analysis/ (accessed on 1 June 2020).

31. HM Treasury. The Green Book; HM Treasury: London, UK, 2018.

32. Citizens Advice. Making A Difference Our Impact in 2018/19; Citizens Advice: London, UK, 2019.

33. New Economy. Emergency Medical Response by Fire and Rescue Services; New Economy: Manchester, UK, 2017.

34. Scott, S.; Botcherby, S.; Ludvigsen, A. Wigan and Rochdale Child Sexual Exploitation Innovation Project; Children's Social Care Innovation Programme Evaluation Report: London, UK, 2017.

35. Hayden, C.; Houghton, J.; Lee, B.; Wilkinson, J. Evaluation of the Our Place Programme: 2014-2015; London, UK, 2016.

36. Morris, D. Valuing Your Impact Cost Benefit Analysis Excel Model User Guide; Manchester, UK, 2019.

37. Alferoff, A. Valuing your impact training-5 March 2019 Feedback; London, UK, 2019.

38. Chambers, R. Rural Development Putting the Last First; Longman Scieintific and Technical: Harlow, UK, 1983; ISBN 0-582-64443-7.

39. Institute of Development Studies Participatory Methods Rapid Rural Appraisal (RRA). Available online: https://www.participatorymethods.org/glossary/rapid-rural-appraisal-rra (accessed on 17 June 2020).

40. Townsley, P. Rapid Rural Appraisal, Participatory Rural Appraisal and Aquaculture; Rome, Italy, 1996.

41. Living Wage Foundation The Calculation. Available online: https://www.livingwage.org.uk/calculation (accessed on 1 June 2020).

42. Heritage Fund. Application Guidance National Lottery Grants for Heritage £10,000- £250,000. Available online: https://www.heritagefund.org.uk/sites/default/files/media/attachments/HF\%20Application\%20Guidance_ B_MEDIUM_v2.pdf (accessed on 1 June 2020).

43. Wood, C.J.; Pretty, J.; Griffin, M. A case-control study of the health and well-being benefits of allotment gardening. J. Pub. Health 2016, 38, E336-E344. [CrossRef]

44. Hoffman, A.J.; Thompson, D.; Cruz, A. Gardening, Self-Efficacy and Self-Esteem. Commun. Coll. Enterp. 2004, 10, 91.

45. Hoffman, A.J.; Knight, L.F.M.; Wallach, J. Gardening Activities, Education, and Self-Esteem Learning Outside the Classroom. Urban Educ. 2007, 42, 403-411. [CrossRef]

46. Kotozaki, Y. Horticultural therapy as a measure for recovery support of regional community in the disaster area: A preliminary experiment for forty five women who living certain region in the coastal area of Miyagi Prefecture. Int. J. Emerg. Ment. Health Hum. Resil. 2014, 16, 114-116.

47. Bragg, R.; Atkins, G. A Review of Nature-Based Interventions for Mental Health Care; Natural England: London, UK, 2017; Volume 204.

48. Adevi, A.A.; Martensson, F. Stress rehabilitation through garden therapy: The garden as a place in the recovery from stress. Urban For. Urban Green. 2013, 12, 230-237. [CrossRef]

49. Harris, N.; Minniss, F.R.; Somerset, S. Refugees Connecting with a New Country through Community Food Gardening. Int. J. Environ. Res. Pub. Health 2014, 11, 9202-9216. [CrossRef]

50. Hartwig, K.A.; Mason, M. Community Gardens for Refugee and Immigrant Communities as a Means of Health Promotion. J. Commun. Health 2016, 41, 1153-1159. [CrossRef] [PubMed]

51. Middling, S.; Bailey, J.; Maslin-Prothero, S.; Scharf, T. Gardening and the Social Engagement of Older People. Work. Older People Commun. Care Policy Pract. 2011, 15, 112-122. [CrossRef]

52. Sempik, J.; Rickhuss, C.; Beeston, A. The effects of social and therapeutic horticulture on aspects of social behaviour. Br. J. Occup. Ther. 2014, 77, 313-319. [CrossRef] 
53. Van den Berg, A.E.; Van Winsum-Westra, M.; De Vries, S.; Van Dillen, S.M. Allotment gardening and health: A comparative survey among allotment gardeners and their neighbors without an allotment. Environ. Health 2010, 9, 74. [CrossRef]

54. Fieldhouse, J. The Impact of an Allotment Group on Mental Health Clients' Health, Wellbeing and Social Networking. Br. J. Occup. Ther. 2003, 66, 286-296. [CrossRef]

55. Kam, M.C.Y.; Siu, A.M.H. Evaluation of a Horticultural Activity Programme for Persons with Psychiatric Illness. Hong Kong J. Occup. Ther. 2010, 20, 80-86. [CrossRef]

56. Hawkins, J.L.; Thirlaway, K.J.; Backx, K.; Clayton, D.A. Allotment Gardening and Other Leisure Activities for Stress Reduction and Healthy Aging. Horttechnology 2011, 21, 577-585. [CrossRef]

57. Kohlleppel, T.; Bradley, J.C.; Jacob, S. A walk through the garden: Can a visit to a botanic garden reduce stress? Horttechnology 2002, 12, 489-492. [CrossRef]

58. Hawkins, J.L.; Smith, A.; Backx, K.; Clayton, D.A. Exercise Intensities of Gardening Tasks Within Older Adult Allotment Gardeners. J. Aging Phys. Act. 2015, 23, 161-168. [CrossRef] [PubMed]

59. Kim, M.Y.; Kim, G.S.; Mattson, N.S.; Kim, W.S. Effects of Horticultural Occupational Therapy on the Physical and Psychological Rehabilitation of Patients with Hemiplegia after Stroke. Korean J. Hortic. Sci. Technol. 2010, 28, 884-890.

60. Leng, C.H.; Wang, J.-D. Daily home gardening improved survival for older people with mobility limitations: An 11-year follow-up study in Taiwan. Clin. Interv. Aging 2016, 11, 947. [CrossRef]

61. Rodiek, S. Influence of An Outdoor Garden On Mood And Stress in Older Persons. J. Ther. Hortic. 2002, 13, 13-21.

62. Zick, C.D.; Smith, K.R.; Kowaleski-Jones, L.; Uno, C.; Merrill, B.J. Harvesting More Than Vegetables: The Potential Weight Control Benefits of Community Gardening. Am. J. Pub. Health 2013, 103, 1110-1115. [CrossRef]

63. Blair, C.K.; Madan-Swain, A.; Locher, J.L.; Desmond, R.A.; De Los Santos, J.; Affuso, O.; Glover, T.; Smith, K.; Carley, J.; Lipsitz, M.; et al. Harvest for health gardening intervention feasibility study in cancer survivors. Acta Oncol. 2013, 52, 1110-1118. [CrossRef]

64. Austin, E.N.; Johnston, Y.A.M.; Morgan, L.L. Community Gardening in a Senior Center: A Therapeutic Intervention to Improve the Health of Older Adults. Ther. Recreat. J. 2006, 40, 48-57.

65. Matsunaga, K.; Park, B.-J.; Kobayashi, H.; Miyazaki, Y. Physiologically Relaxing Effect of a Hospital Rooftop Forest on Older Women Requiring Care. J. Am. Geriatr. Soc. 2011, 59, 2162-2163. [CrossRef]

66. Glover, D.; Henderson, J. Quantifying Health Impacts of Government Policies; London, UK, 2010.

67. Michaelson, J.; Abdallah, S.; Steuer, N.; Thompson, S.; Marks, N. National Accounts of Well-being: Bringing Real Wealth onto the Balance Sheet; New Economics Foundation: London, UK, 2009.

68. Cox, J.; Bowen, M.; Kempton, O. Social Value: Understanding the Wider Value of Public Policy Interventions; Manchester, UK, 2012.

69. Schoen, V. Personal communication with Julian Cox 2020.

70. Parkinson, M. Email exchange regarding price data for organic produce 2020.

71. Vining, A.; Weimer, D.L. An Assessment of Important Issues Concerning the Application of Benefit-Cost Analysis to Social Policy. J. Benefit Cost Anal. 2010, 1, 1-40. [CrossRef]

72. NHS Improvement. Reference Costs 2017/18: Highlights, Analysis and Introduction to the Data; London, UK, 2018.

73. NICE. Alcohol Use Disorders Diagnosis, Assessment and Management of Harmful Drinking and Alcohol Dependence; London, UK, 2010.

74. NICE. Alcohol-Use Disorders: Diagnosis, Assessment and Management of Harmful Drinking (High-Risk Drinking) and Alcohol Dependence. Clinical Guidance 115; London, UK, 2011.

75. Martellozzo, F.; Landry, J.-S.; Plouffe, D.; Seufert, V.; Rowhani, P.; Ramankutty, N. Urban agriculture: A global analysis of the space constraint to meet urban vegetable demand. Environ. Res. Lett. 2014, 9, 64025. [CrossRef]

76. Lin, B.B.; Philpott, S.M.; Jha, S. The future of urban agriculture and biodiversity-ecosystem services: Challenges and next steps. Basic Appl. Ecol. 2015, 16, 189-201. [CrossRef]

77. Walters, S.A.; Midden, K.S. Sustainability of Urban Agriculture: Vegetable Production on Green Roofs. Agric. Basel 2018, 8, 168. [CrossRef] 
78. Federation of City Farms and Community Gardens. How Community Gardens can Contribute to Biodiversity; FCFCG: Edinburgh, UK, 2016.

79. Acton, L. Growing Space: A History of the Allotment Movement; Five Leaves Publications: Nottingham, UK, 2015.

80. Bell, S.; Fox-Kämper, R.; Keshavarz, N.; Benson, M.; Caputo, S.; Noori, S.; Voigt, A. Urban Allotment Gardens in Europe, 1st ed.; Routledge: London, UK, 2016.

81. Draper, C.; Freedman, D. Review and Analysis of the Benefits, Purposes, and Motivations Associated with Community Gardening in the United States. J. Commun. Pract. 2010, 18, 458-492. [CrossRef]

82. Firth, C.; Maye, D.; Pearson, D. Developing "community" in community gardens. Local Environ. 2011, 16, 555-568. [CrossRef]

83. Levidow, L. London's urban agriculture: Building community through social innovation. Int. J. Soc. Agric. Food 2018, 24, 354-376.

84. Philips, A. Designing Urban Agriculture: A Complete Guide to the Planning, Design, Construction, Maintenance and Management of Edible Landscapes, 1st ed.; Wiley: Hoboken, NJ, USA, 2013.

85. Milne, C. Mental Health Spending in the English NHS. Available online: https://fullfact.org/health/mentalhealth-spending-england (accessed on 1 June 2020).

86. Greater London Authority. The London Food Strategy Healthy and Sustainable Food for London; Greater London Authority: London, UK, 2018.

87. Hardman, M.; Larkham, P.J. The rise of the 'food charter': A mechanism to increase urban agriculture. Land Use Policy 2014, 39, 400-402. [CrossRef]

88. Sydenham Garden. Sydenham Garden A Growing Opportunity. Available online: https://www. sydenhamgarden.org.uk (accessed on 1 June 2020).

89. Brighton and Hove City Council. PAN 06 Food Growing and Development; The Local Development Team; Brighton \& Hove City Council: Hove, UK, 2011; Volume 6.

90. Sustainable Food Places Sustainable Food Places. Available online: https://www.sustainablefoodplaces.org (accessed on 1 June 2020).

(C) 2020 by the authors. Licensee MDPI, Basel, Switzerland. This article is an open access article distributed under the terms and conditions of the Creative Commons Attribution (CC BY) license (http://creativecommons.org/licenses/by/4.0/). 